Check for updates

Cite this: Mater. Chem. Front., 2019, 3, 636

Received 16th October 2018 Accepted 13th February 2019

DOI: $10.1039 / c 8 q m 00527 c$

rsc.li/frontiers-materials

\title{
Synthesis of a surface mounted metal-organic framework on gold using a Au-carbene self-assembled monolayer linkage $\dagger$
}

\author{
Esther Frederick, $\ddagger^{a}$ Travis W. Shaw, ${ }^{a}$ Matthew G. Frith $\S^{a}$ and \\ Steven L. Bernasek (iD *ab
}

\begin{abstract}
Applications using metal-organic frameworks (MOFs) in devices require a degree of positional control that necessitates an attachment more robust than direct MOF growth on a bare substrate. To date, the precise positioning of MOFs on Au surfaces has been accomplished using thiol-Au linkages, which lack the long-term stability needed for device applications. This study utilized a Au-carbene monolayer with long term stability developed by Crudden et al. as the linkage between a gold substrate and MOF. The Au-carbene surface mounted MOF (surMOF) was successfully synthesized using layer by layer deposition and characterized using XRD, XPS, and AFM.
\end{abstract}

\section{Background}

Metal-organic frameworks (MOFs) are a versatile material with high porosity, ${ }^{1}$ surface area, ${ }^{2}$ and potential for post-functionalization. ${ }^{3}$ They have been extensively researched and are of interest for numerous applications $;^{4-11}$ including natural gas vehicles, ${ }^{5}$ molecular storage, ${ }^{6,7}$ catalysis, ${ }^{8}$ separations, ${ }^{9}$ medicine, ${ }^{10}$ and commercial success in the food industry. ${ }^{11}$ Applications using MOFs in devices require positional control of the $\mathrm{MOF}^{12}$ which requires a more robust attachment than provided by the direct growth of the MOF on a bare substrate. One promising method involves growing a MOF on a functionalized substrate ${ }^{13-16}$ such as a self-assembled monolayer (SAM). ${ }^{17}$ Previous attachments to gold substrates rely on Au-thiol linkages, ${ }^{13-16}$ which have limited stability and undergo rapid degradation in ambient conditions. ${ }^{18}$ In this work, an Au surface mounted MOF (surMOF) was successfully

\footnotetext{
${ }^{a}$ Department of Chemistry, Princeton University, Princeton, NJ, 08544, USA.

E-mail:sberna@princeton.edu

${ }^{b}$ Science Division, Yale-NUS College, 138527, Singapore.

E-mail:steven.bernasek@yale-nus.edu.sg

$\dagger$ Electronic supplementary information (ESI) available: Detailed experimental methods for carbene synthesis (SI 1), surface functionalization (SI 2), and surface characterization (SI 3). XPS, AFM and ATR-FTIR experimental data can be found in SI 4. XPS data includes spectra of the sample after SAM formation, after click modification of the SAM to alter the terminating group to a carboxylic acid, and after surMOF deposition. AFM images obtained after carboxylic acid modification and after surMOF formation. ATR-FTIR spectra of sample after XRD (PDF). See DOI: $10.1039 / \mathrm{c} 8 \mathrm{qm} 00527 \mathrm{c}$

\$ Present address: Department of Chemistry and Biochemistry, University of California, San Diego, La Jolla, California, 92093, USA.

$\S$ Present address: X-ray Science Division, Argonne National Laboratory, Argonne, IL, 60439, USA.
}

synthesized and characterized using a carbene linkage based on self-assembled monolayer work by Crudden et $a{ }^{19}{ }^{19}$ followed by a layer by layer MOF deposition method to form a surMOF. The robust carbene-Au bond surMOF provides a platform to utilize Au substrates in devices requiring positional control of MOFs.

Carbenes are a highly utilized ligand that bind to metals through a lone pair of electrons on neutral carbon atoms. ${ }^{20}$ To increase stability, two heteroatoms can be added adjacent to the carbene atom to form a $n$-heterocyclic carbene. ${ }^{21}$ Crudden et al. developed novel gold surface linkages based on Au-carbene chemistry ${ }^{19}$ which display long range order and stability under a variety of organic, aqueous, $\mathrm{pH}$, and temperature conditions, due to their high desorption barrier. ${ }^{22}$ Experimental studies of stability were supported in the same work with density functional theory methods, which calculated the most stable carbene-Au binding mode as $25 \mathrm{~kJ} \mathrm{~mol}^{-1}$ stronger than the Au-S bond energy. ${ }^{19}$ Additionally, the azide termination of the SAM allows for versatile post-modification to easily alter SAM properties.

In this work, an Au-carbene SAM was used as a foundation for a novel gold mounted metal-organic framework (Fig. 1). The azide terminated SAM was modified to form a carboxylic acid termination. The step-by step building of a surMOF on the SAM was demonstrated to successfully form a surMOF linked to a Au substrate via a robust Au-linkage.

\section{Experimental methods}

Carbene synthesis and surface functionalization were done using adapted literature methods (Fig. 2). ${ }^{19,23}$ See ESI $\dagger$ for details about carbene synthesis (SI 1) and surface functionalization (SI 2). 


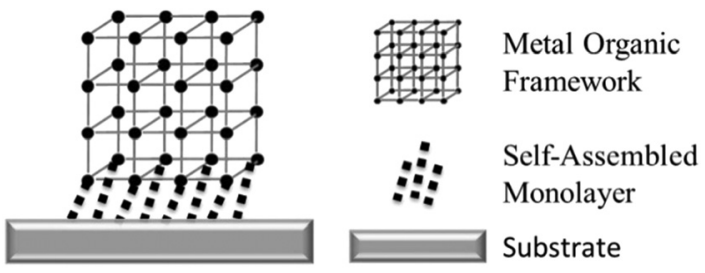

Fig. 1 Schematic of a surface mounted MOF using a self-assembled monolayer to attach the MOF to the substrate.

The Cu-biphenyl dicarboxylic acid ( $\mathrm{Cu}(\mathrm{bpdc}))$ surMOF was built using a layer by layer deposition method (Fig. 3). AFM, XPS, and grazing incidence XRD were used to confirm SAM formation, successful post-modification and surMOF deposition. Detailed surface characterization information is available in the $\mathrm{ESI} \dagger$ (SI 3).

\section{Results and discussion}

\section{Step 1: attachment of azide terminated SAM to Au substrate via carbene linkage}

XPS was used to confirm the successful formation of the SAM via a carbene-Au linkage (SI 4 and Fig. SI 7, ESI $\dagger$ ). The presence of an $\mathrm{N} 1 \mathrm{~s}$ peak at $400.5 \mathrm{eV}$, with a residual of 1 , matched the published $\mathrm{N}$ 1s binding energy for electron-rich azide nitrogen atoms. ${ }^{24}$ The $\mathrm{C} 1 \mathrm{~s}$ region was fit to three peaks with a residual of 1.6. The $\mathrm{C} 1 \mathrm{~s}$ peak at $284.8 \mathrm{eV}$ was attributed to adventitious $\mathrm{C}$ and $\mathrm{C}-\mathrm{C}$ and $\mathrm{C}-\mathrm{H}$ bonds from the functionalizing molecule, the peak at $285.9 \mathrm{eV}$ was attributed to a $\mathrm{C}-\mathrm{N}$ bond and corresponded well to literature values of $286.0 \mathrm{eV},{ }^{25}$ and the peak at $287.3 \mathrm{eV}$ was attributed to the carbene species whose C 1s binding energy was shifted to higher binding energy due to bonding with two adjacent nitrogen atoms. The Au effects on shift to lower binding energy was minimal compared to the effect of the nitrogen atoms due to the greater electronegativity difference between $\mathrm{N}$ and $\mathrm{C}$ than $\mathrm{Au}$ and $\mathrm{C}$, and less significantly, due to bonding with two $\mathrm{N}$ atoms versus bonding to only one Au atom. O 1s displayed a single peak, residual of 1 , at $532.2 \mathrm{eV}$ attributed to adventitious contamination.

AFM after the next step of carboxylic acid modification was used to further confirm surface functionalization (SI 4 and Fig. SI 8, SI 9, ESI $\dagger$ ). A decrease in RMS for height images from 10 on the bare sample to $3 \mathrm{~nm}$ on the modified substrate
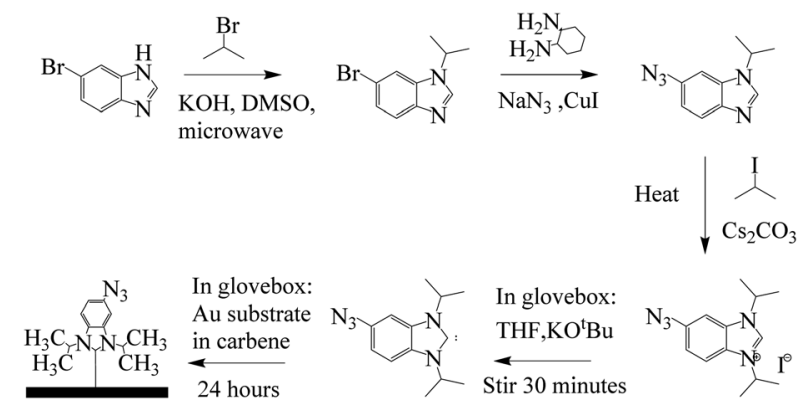

Fig. 2 Scheme for Au-carbene SAM synthesis modified from the literature. ${ }^{25}$

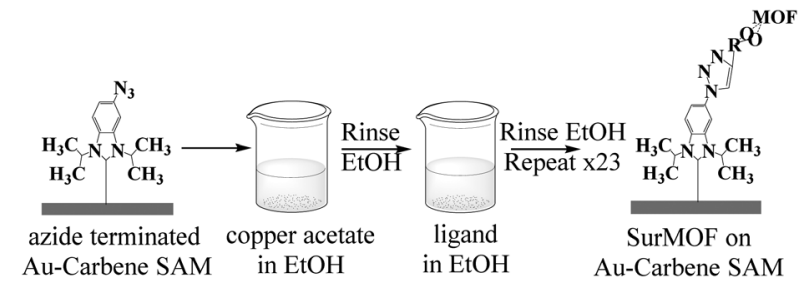

Fig. 3 Schematic of building SurMOF using layer-by-layer deposition.

indicated greater uniformity attributed to SAM functionalization. Phase images displayed a visible change, with an increase of RMS to 16 from a RMS of 5 on the bare substrate indicating a greater variation in chemical composition due to surface functionalization.

\section{Step 2: post-modification to form COOH terminated SAM}

XPS was used to confirm the successful click chemistry postmodification of the SAM to alter the terminating group to a carboxylic acid (SI 4 and Fig. SI 10, ESI†). The C 1s region was fit to three peaks with a residual of 1.1 The $284.8 \mathrm{eV} \mathrm{C} 1 \mathrm{~s}$ peak corresponded to adventitious $\mathrm{C}$ and $\mathrm{C}-\mathrm{C}$ and $\mathrm{C}-\mathrm{H}$ bonds from the sample, the $285.7 \mathrm{eV}$ peak was from the $\mathrm{C}-\mathrm{N}$ bond, ${ }^{25}$ and the $288.8 \mathrm{eV}$ peak was attributed to the carboxylic acid carbon corresponding to literature values of $289.1 \mathrm{eV} .{ }^{26}$ The $\mathrm{O} 1 \mathrm{~s}$ region displayed two peaks, at $530.4 \mathrm{eV}$ and the one at $531.8 \mathrm{eV}$, as compared with the one peak of the azide terminated SAM, with a residual of 1.1. The peak at $531.8 \mathrm{eV}$ corresponds well to the published ${ }^{26}$ carboxylic acid O shift of $532.0 \mathrm{eV}$ (carbonyl) atoms. The $\mathrm{N}$ 1s region displayed three peaks at $401.8 \mathrm{eV}, 400.1 \mathrm{eV}$, and $398.0 \mathrm{eV}$ with a residual of 0.97 . The $401.8 \mathrm{eV}$ and $400.1 \mathrm{eV}$ peaks were assigned, as with the azide terminated SAM, to the azide nitrogen atoms. The new peak at a lower binding energy was ascribed to the newly formed $\mathrm{N}-\mathrm{C}$ bond of the triazole. ${ }^{24}$ Overall, the presence of a $\mathrm{C} 1 \mathrm{~s}$ peak at $288.8 \mathrm{eV}$, two peaks in the $\mathrm{O} 1 \mathrm{~s}$ region, and triazole presence in the $\mathrm{N} 1 \mathrm{~s}$ region was in agreement to observed XPS binding energies in similar systems, ${ }^{19}$ confirming the success of the reaction. The presence of an azide peak in the $\mathrm{C} 1 \mathrm{~s}$ and $\mathrm{N}$ 1s spectra indicated that the SAM was not completely converted to a $-\mathrm{COOH}$ terminated SAM.

\section{Step 3: formation of surMOF}

XPS (SI 4 and Fig. SI 11, ESI $\dagger$ ) and XRD (Fig. 4) measurements of samples post-surMOF attachment demonstrated successful surMOF synthesis. XPS of the $\mathrm{Cu}$ region displayed a peak fit with a residual of 1.6. The broad peak at $932.2 \mathrm{eV}$ corresponded to literature values for $\mathrm{Cu}$ ion species, and the $940.9 \mathrm{eV}$ peak was attributed to a $\mathrm{Cu}(\mathrm{II})$ shakeup peak. ${ }^{27}$ The $\mathrm{O} 1 \mathrm{~s}$ region displayed a single peak at $532.3 \mathrm{eV}$, residual of 1.1, which conforms well to published $\mathrm{O} 1 \mathrm{~s}$ values of $532.5 \mathrm{eV}$ for broad peaks inclusive of $-\mathrm{COOH}$ and $-\mathrm{COO}-$ species. $^{28}$ The $\mathrm{C} 1 \mathrm{~s}$ region displayed two peaks with a residual of 1 , with a large peak at $284.8 \mathrm{eV}$ corresponding to adventitious $\mathrm{C}$ and $\mathrm{C}-\mathrm{C}$ and $\mathrm{C}-\mathrm{H}$ bonds from the surMOF molecules and a peak at $288.8 \mathrm{eV}$ consistent with literature values for $\mathrm{COO}-$ and $-\mathrm{COOH}$ species. ${ }^{26}$ The $\mathrm{C} 1 \mathrm{~s}$ peak did not indicate the presence of a $\mathrm{C}-\mathrm{N}$, however, that was likely due to a lack of resolution as nitrogen containing species were 


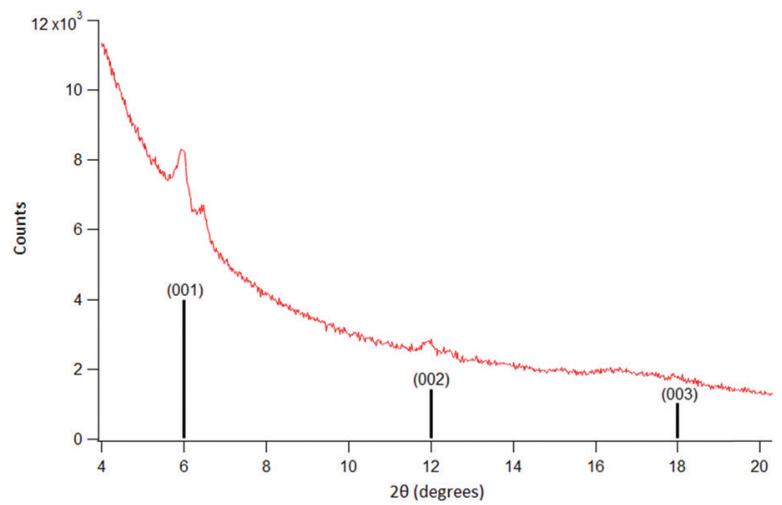

Fig. 4 Measured data (red, top) (Cu K $\alpha 1.5418 \AA$ ) and line representation of published XRD data (black, bottom) for out of plane reflection for tetragonal P4 structure identified for $\mathrm{Cu}(\mathrm{bpdc})$ in ref. 14. The set of larger peaks in the experimental data matched the literature patterns. The set of small peaks is due to the formation of a second crystalline structure which appeared after several hours of XRD data collection.

present in the $\mathrm{N}$ 1s region, which displayed a single peak at $398.2 \mathrm{eV}$, residual 1, attributed to the $\mathrm{N}-\mathrm{C}$ bond of the triazole. ${ }^{27}$ The observation of this signal, which is normally weak, was likely due to the surMOF porosity and non-uniformity of the coverage which may allow for greater X-ray penetration and electron escape depth. Overall, the XPS spectra, particularly the presence of peaks in the $\mathrm{Cu}$ region, provides evidence of $\mathrm{Cu}$ and $-\mathrm{COOH}$ species.

XRD measurements confirmed the molecules were deposited in an organized surMOF structure. The XRD spectra displayed large peaks around $2 \theta$ values of 6 and 12, and a broad peak stretching from 17-18 $2 \theta$ (Fig. 4) which matched previously published peak values for a $\mathrm{Cu}(\mathrm{bpdc})$ surMOF with three peaks around $2 \theta$ values of 6,12 , and $18 .{ }^{14}$ A second set of smaller peaks at $2 \theta$ values of $6.5,12.4$, and $17-18$ appeared after several hours of scanning and were likely due to XRD induced changes in the surMOF material.

Noticeable changes in the surface appearance were visible by eye post-XRD in the exposed region. While initially attributed to structural decomposition, the appearance of smaller peaks at $6.5,12.4$ and $17-182 \theta$ peaks during later scan times suggested the visible change may be due to the formation of a second, ordered crystalline structure on the surface. ATR-FTIR on both XRD and non-XRD exposed regions of the same sample (SI 4 and Fig. S 12, ESI $\dagger$ ) further show that the XRD exposed region displayed a peak at $2921 \mathrm{~cm}^{-1}$, which corresponds to the presence of hydrocarbon species. As data was acquired from the same sample, the results indicate the presence of a new species rather than adsorption of adventitious molecules onto the surface or into the MOF over the course of the overnight scans. A change in the chemical composition of the surMOF or integration of a newly formed species diffusion limited to the local area would lead to a new set of weaker peaks in the XRD spectra. This may be of interest to explore in future work.

AFM images (SI 4 and Fig. SI 13, ESI $\dagger$ ) were obtained to gain an understanding of the surMOF structure. Interestingly, the AFM displayed irregularly shaped islands with phase images indicating that the borders of the surMOF islands differ in chemical composition from the center.

\section{Conclusions}

A novel Au mounted surMOF was successfully synthesized using a carbene linkage and layer by layer surMOF deposition methods. AFM, XPS and XRD results suggest the successful formation of the surMOF. The results of this study indicate that the change in SAM morphology did not affect the successful formation of the surMOF and its morphology. The synthetic method demonstrated in this work is highly versatile as there are many choices for metal terminations and MOF structures. The interchangeability of the carbene-based layer-by-layer surMOF components makes them useful in a wide variety of future studies. Longer XRD scan times resulted in diffraction patterns suggesting the presence of a second crystalline phase as a result of X-ray irradiation. This unexpected result may be of interest for exploration in future work.

\section{Conflicts of interest}

There are no conflicts to declare.

\section{Acknowledgements}

This work was partially supported by the National Science Foundation, Division of Chemistry, CHE-1213216, the Division of Materials Research, DMR-1506989. EF and TWS acknowledges the support of NSF-GRFP for funding.

\section{References}

1 O. M. Yaghi, G. Li and H. Li, Nature, 1995, 378, 703.

2 O. K. Farha, I. Eryazici, N. C. Jeong, B. G. Hauser, C. E. Wilmer, A. A. Sarjeant, R. Q. Snurr, S. B. T. Nguyen, O. Yazaydin and J. T. Hupp, J. Am. Chem. Soc., 2012, 134, 15016.

3 S. M. Cohen, Chem. Rev., 2012, 112, 970.

4 (a) H. Zhou, J. R. Long and O. M. Yaghi, Chem. Rev., 2012, 112, 673; (b) J. R. Long and O. M. Yaghi, Chem. Soc. Rev., 2009, 38, 1201; (c) S. Kitagawa and H. C. Zhou, Chem. Soc. Rev., 2014, 43, 5415; (d) O. Shekhah, J. Liu, R. A. Fischer and C. Wöll, Chem. Soc. Rev., 2011, 40, 1081.

5 BASF, Chem. Soc. Rev., 2014, 43, 6173.

6 R. B. Getman, Y. Bae, C. E. Wilmer and R. Q. Snurr, Chem. Rev., 2012, 112, 703.

7 Y. Bai, Y. Dou, L. Xie, W. Rutledge, J. Li and H. Zhou, Chem. Soc. Rev., 2016, 45, 2327.

8 Y. Liu, A. J. Howarth, N. A. Vermeulen, S. Y. Moon, J. T. Hupp and O. K. Farha, Coord. Chem. Rev., 2016, 346, 101.

9 J. R. Li, J. Sculley and H. C. Zhou, Chem. Rev., 2012, 112, 869. 10 S. Wuttke, S. Braig, T. Preis, A. Zimpel, J. Sicklinger, C. Bellomo, J. O. Radler, A. M. Vollmar and T. Bein, Chem. Commun., 2015, 51, 15752.

11 MOF Technologies Announces World's First Commercial Application of Metal Organic Framework Technology by 
Decco Worldwide at MOF 2016. Published 09/13/2016, http://www.moftechnologies.com/2016/09/13/mof-announcesworlds-first-commercial-application-decco-worldwide-mof-2016/ 2017.

12 V. Stavila, A. A. Talin and M. D. Allendorf, Chem. Soc. Rev., 2014, 43, 5994.

13 P. Falcaro, R. Ricco, C. M. Doherty, K. Liang, A. J. Hill and M. J. Styles, Chem. Soc. Rev., 2014, 43, 5513.

14 J. Liu, B. Lukose, O. Shekhah, H. K. Arslan, P. Weidler, P. H. Gliemann, S. Brase, S. Grosjean, A. Godt, X. Feng, K. Mullen, I. B. Magdau, T. Heine and C. Wöll, Nat. Sci. Rep., 2012, 2, 1.

15 S. Hermes, F. Schroder, R. Chelmowski, C. Wöll and R. A. Fischer, J. Am. Chem. Soc., 2005, 127, 13744.

16 H. Gliemann and C. Wöll, Mater. Today, 2012, 15, 110.

17 E. P. Valadez Sánchez, H. Gliemann, K. Haas-Santo, C. Wöll and R. Dittmeyer, Chem. Ing. Tech., 2016, 88, 1798.

18 T. M. Willey, A. L. Vance, T. van Buuren, C. Bostedt, L. J. Terminello and C. S. Fadley, Surf. Sci., 2005, 576, 188.

19 C. M. Crudden, J. H. Horton, I. I. Ebralidze, O. V. Zenkina, A. B. McLean, B. Drevniok, Z. She, H. Kraatz, N. J. Mosey, T. Seki, E. C. Keske, J. D. Leake, A. Rousina-Webb and G. Wu, Nat. Chem., 2014, 6, 409.

20 (a) A. Geuther and M. Hermann, Liebigs Ann. Chem., 1855, 95, 211; (b) P. de Frémont, N. Marion and S. P. Nolan, Coord. Chem. Rev., 2009, 253, 862.
21 (a) A. Igau, H. Grützmacher, A. Baceiredo and G. Bertrand, J. Am. Chem. Soc., 1988, 110, 6463; (b) A. J. Arduengo, R. L. Harlow and M. A. Kline, J. Am. Chem. Soc., 1991, 113, 361; (c) W. A. Herrmann, Angew. Chem., Int. Ed., 2002, 41, 1290; (d) E. Peris and R. H. Crabtree, Coord. Chem. Rev., 2004, 248, 2239.

22 G. Wang, A. Rahling, S. Amirjalayer, M. Knor, J. B. Ernst, C. Richter, H. Gao, A. Timmer, H. Gao, N. L. Doltsinis, F. Glorius and H. Fuchs, Nat. Chem., 2017, 9, 152.

23 (a) O. V. Starikova, G. V. Dolgushin, L. I. Larina, P. E. Ushakov, T. N. Komarova and V. A. Lopyrev, Russ. J. Org. Chem., 2003, 39(10), 1467; (b) J. Andersen, U. Madsen, F. Björkling and X. Liang, Synlett, 2005, 2209.

24 T. Heinrich, C. H. Traulsen, E. Darlatt, S. Richter, J. Poppenberg, N. L. Traulsen, I. Linder, A. Lippitz, P. M. Dietrich, B. Dib, W. E. S. Unger and C. A. Schalley, RSC Adv., 2014, 4, 17694.

25 B. Kumar, M. Asadi, D. Pisasale, S. Sinha-Ray, B. A. Rosen, R. Haasch, J. Abiade, A. L. Yarin and A. Salehi-Khojin, Nat. Commun., 2013, 4, 2819.

26 C. M. Whelan, J. Ghijsen, J. Pireaux and K. Maex, Thin Solid Films, 2004, 464, 388-392.

27 M. C. Biesinger, L. W. M. Lau, A. R. Gerson and R. S. C. Smart, Appl. Surf. Sci., 2010, 257, 887.

28 T. A. Daniel, S. Uppili, G. McCarty and D. L. Allara, Langmuir, 2007, 23, 638. 